To the Editors:

\title{
Anal incontinence in the ageing Sri Lankan population: the results of a pilot study
}

Anal incontinence is a disability resulting in social exclusion and loss of self-confidence. It is widely accepted that many patients with anal incontinence do not seek medical advice, making the true prevalence uncertain. In the UK, France and Germany prevalence in the community varies from 4.8 to $13 \%[1,2,3]$. Independent risk factors for anal incontinence include female gender, advancing age, poor general health and physical impairment. In women, childbirth associated damage to perineal structures is the primary causative factor [4]. Despite having an ageing population, there are no studies regarding the prevalence, aetiology or disability of anal incontinence among Sri Lankans.

We conducted a prospective study on 347 patients admitted to the National Hospital of Sri Lanka with nongastrointestinal problems using a validated questionnaire [5]. Comparison between groups was done using Fisher's exact test (two-tailed).

The mean age of our study population was 65 (range 50-91) years. Male to female ratio was 13:10.29 patients $(8.36 \%)$ complained of anal incontinence: incontinence to flatus was seen in $23(79 \%)$, to liquid faeces in $9(31 \%)$, to solid faeces in $4(13 \%)$ and to all three in $1(3.4 \%)$. Eighteen $(62 \%)$ of the incontinent were women. Nine $(31 \%)$ complained of disruption of their physical and social activity. The mean Cleveland incontinence score [4] was 3 (range1-9). Of the incontinent women, 13 (72\%) had undergone two or more vaginal deliveries with $8(44 \%)$ of them having 4 or more deliveries.
Our pilot study shows that anal incontinence is as common here as in western series. Although we could not find a definite aetiological factor for anal incontinence among men, the commonest aetiological factor causing incontinence in women appears to be vaginal delivery. Nearly one-third of incontinent patients also had their social and physical life affected by the symptoms. Larger community based studies are needed to validate our findings.

\section{References}

1. Johanson JF, Lafferty J. Epidemiology of faecal incontinence: the silent affliction. American Journal of Gastroenterology 1996; 91: 33-6.

2. Denis P, Bercoff E, Bizien MF, Broccker P, Chassagne P. Etude de la prevalence de l'incontinence anale chez l'adilte. Gastroenterologie Clinique et Biologique 1992: 16: 344-50.

3. Thomas TM, Egan M, Walgove A, Meade TW. The prevalence of faecal and double incontinence. Community Medicine 1984; 6: 216-20.

4. MacArthur C, Bick D, Keighly M. Faecal incontinence after childbirth. British Journal of Obstetrics and Gynaecology 1997; 104: 46-50.

5. Jorge JMN, Wexner SD. Etiology and Management of faecal incontinence. Diseases of the Colon and Rectum 1993; 36: 77-97.

N D Premachandra, S W Kotalawala, R Cooray and D N Samarasekera, University Surgical Unit, National Hospital of Sri Lanka, Colombo.

Correspondence: DNS, e-mail: <samarasekera58@yahoo.co.uk>. Received 25 January 2008 and revised version accepted 3 July 2008. Competing interests: none declared. 